\title{
Moncada González, Gisela (2013), La libertad comercial. El sistema de abasto DE alimentos en la CiUdad de MÉxICO, 1810-1835, MÉXICo: Instituto Mora.
}

\author{
María Eugenia Claps-Arenas
}

E n el libro La libertad comercial. El sistema de abasto de alimentos en la ciudad de México, 1810-1835, Gisela Moncada se adentra en el interesante y novedoso tema del abasto de alimentos para las ciudades, en este caso, la de México, durante los años que comprenden desde el inicio del movimiento de Independencia (1810) hasta el fin de la primera república federal (1835), época sin duda muy significativa y convulsa en la historia del país ya que supuso el tránsito de la Nueva España, parte integrante del imperio español, a las primeras décadas del Estado mexicano independiente; es decir, se ocupa del fenómeno del abasto de alimentos en dos ámbitos jurídico gubernamentales diferentes de la historia del país.

De manera central, la investigación se propone responder al siguiente cuestionamiento: ¿cómo garantizaron las autoridades, tanto virreinales como nacionales, el abasto de alimentos para la gran ciudad durante los años enunciados en el título? Cabe aquí señalar que este tipo de estudios en la historiografía son recientes y, por su capacidad explicativa de los procesos históricos, su análisis resulta fundamental. Asimismo, es importante apuntar que se inserta en un esfuerzo de conjunto ya que la obra forma parte de la colección
Historia económica del Instituto de Investigaciones Dr. José María Luis Mora.

En la introducción, la autora explica que la publicación explora dos sistemas de abasto que respondieron a dos circunstancias políticas distintas: el proteccionismo implementado por la corona española y la libertad comercial auspiciada por la nación independiente. Sin embargo, resulta pertinente apuntar que estos dos sistemas no se produjeron de manera absoluta en ninguno de los casos señalados ya que, por ejemplo, durante la ocupación francesa de España (1808-1814), la corona se vio obligada a flexibilizar mucho su política económica respecto de sus posesiones ultramarinas, por lo que liberó algunos aspectos importantes de la actividad comercial entre éstas y otras naciones. Una reflexión similar puede hacerse para el caso de la primera república federal mexicana, ya que algunos de los secretarios de Hacienda durante ese período, entre ellos José Ignacio Esteva, implementaron políticas proteccionistas durante su gestión. Existen estudios recientes que se ocupan de este tema - como la obra de Leonor Ludlow titulada Los secretarios de Hacienday sus proyectos, 1821-1933, publicada por la UNAM - cuya revisión resulta fundamental sobre

\footnotetext{
María Eugenia Claps Arenas, profesora-investigadora del Centro de Estudios Superiores de México y Centroamérica de la Universidad de Ciencias y Artes de Chiapas, México. Correo electrónico: marigencingen@yahoo.com.
}

Recibida: 30 de junio de 2014. 
todo si tomamos en cuenta, como la propia autora apunta, que "Una de las hipótesis que esta investigación demuestra es que la libertad en el comercio fue la que reguló el sistema de abasto de alimentos en la ciudad de México tras la caída del gobierno virreinal, de esta forma, el proteccionismo paulatinamente fue perdiendo terreno en la política económica de la república después de haber permanecido casi durante tres siglos".

No obstante, Moncada matiza más adelante esta afirmación al abordar el tema del debate político que se produjo entre el proteccionismo y la libertad comercial, cuando apunta que en 1811 las autoridades novohispanas se vieron obligadas a decretar la libertad de precio y expendio de la carne: "Esta disposición fue el parteaguas entre la política proteccionista dirigida al consumidor dictada bajo el virreinato y la política de tintes liberales que surgió en los últimos años del régimen virreinal". Ello se debió, como bien explica este estudio, a que el movimiento encabezado por Miguel Hidalgo en 1810 impactó negativamente en la distribución y regulación de la venta de comestibles para la ciudad de México, sobre todo entre 1810 y 1815, fenómeno que coincidió con la crisis agrícola de 1809-1811. Finalmente, la libertad de precios terminaría por extenderse en estos últimos años de la gestión virreinal a otros productos de consumo básico, como las harinas, las velas y los granos en general.

Ahora bien, la autora considera que una de las contribuciones importantes de su estudio es la de mostrar que, pese a la inestabilidad económica que vivió la ciudad de México tras el levantamiento armado de 1810, durante la república comenzó en la ciudad un lento crecimiento económico del que hasta ahora la historiografía no había dado cuenta. De esta manera, entre 1810 y 1835, no se presentó un déficit en las finanzas municipales y gracias al ingreso del abasto de alimentos se robusteció la economía de la ciudad de México. Es decir, la libertad comercial fue la alternativa utilizada por el gobierno municipal para dirigir el sistema de abasto en la urbe.

El organismo encargado de garantizar el abasto de comestibles a la ciudad de México fue el ayuntamiento. Por ello, la autora ofrece a los lectores en el primer capítulo una relación de las funciones de dicho órgano, entre las postrimerías de la época virreinal y la república (1817-1835), así como un cuadro en el que se detallan, con la precisión que la fuente documental permite, las comisiones que lo integraron con los nombres y cargos de sus responsables. Asimismo, el trabajo presenta una relación del origen social de los miembros que compusieron el ayuntamiento, todos ellos provenientes de familias económicamente poderosas. Otra de las características de esta institución fue el rechazo al régimen virreinal, así como una vocación ilustrada.

La libertad de precio y expendio concedida a los alimentos ocasionó durante los años de la insurgencia, e incluso posteriormente, un incremento en los precios de los alimentos y el aumento de comerciantes en las calles de la ciudad, así como de intermediarios.

De cualquier manera, la disyuntiva que se presentó en esos años, entre la política proteccionista y el libre mercado en lo relativo a los alimentos de primera necesidad, llevó a la autora a hacer un análisis del pensamiento económico de los políticos del siglo XIX y a la identificación de los principales referentes ideológicos para los integrantes del ayuntamiento. Entre los autores citados en las sesiones de cabildo prevalecieron los ilustrados españoles, así como Adam Smith. La información de este capítulo del libro procede entonces básicamente de las actas de cabildo del ayuntamiento de la ciudad de México y corresponde al período de la guerra de Independencia, cuando la mayoría de las voces se pronunciaron a favor de la libertad comercial, ya que se estimaba que ésta generaría abundancia de productos y precios más bajos. Ahora bien, hay que considerar que los integrantes del ayuntamiento que apoyaban la libertad de precios en los comestibles lo hacían porque era una forma de manifestar su rechazo al régimen virreinal. Así, las actas de cabildo evidencian que a partir del movimiento insurgente de 1810 hubo una creciente manifestación de la opinión contraria a los monopolios y proclive a la libre competencia en el comercio.

Sin embargo, Moncada llama acertadamente la atención sobre el hecho de que en este período de transición entre virreinato y nación independiente 
fue común que los políticos y pensadores estuvieran a caballo entre dos formas de concebir la política económica: el proteccionismo y la libertad comercial, y que apoyaran una u otra dependiendo del asunto del que se tratara. Ambos aspectos seguirían debatiéndose durante la primera república federal.

Más adelante encontramos en esta investigación un análisis de la composición de las finanzas que comprende los rubros de ingresos y egresos del ayuntamiento. A raíz de ello, la autora pudo concluir que la entrada de recursos por el cobro de impuesto a los comestibles —es decir, el derecho municipal—, además del cobro por el arrendamiento de plazas y mercados, constituyó la base económica para el citado organismo.

Después, la autora trata el tema de la venta de alimentos que ingresaron a la ciudad de México entre los años 1817 y 1835 , para lo cual utiliza el fondo documental hacienda, cuentas municipales y de plaza remitidas a la aduana del Archivo Histórico del Distrito Federal. Lo que se consideró para hacer esta parte del estudio fue el de comestibles, que la tesorería del ayuntamiento de México tenía bajo su recaudación fiscal a través del cobro del derecho municipal, los cuales eran de alto consumo en la capital. A este respecto, Moncada advierte que sólo pudo considerar los rubros registrados en la tesorería, por lo que los productos que ingresaron de manera ilícita, y de los que por lo tanto no se tiene registro, no pudieron ser considerados.

Ahora bien, a pesar de lo anterior, es importante señalar que el trabajo se sustenta en una sólida investigación documental que permitió la elaboración de cuadros, gráficas, mapas y planos que ofrecen un panorama bastante completo del comportamiento de los distintos rubros comerciales abordados en el trabajo, así como la ubicación de las garitas por donde se introducían legalmente los productos a la capital.

En este libro encontramos también un análisis de la población que integraba la ciudad de México, una de las más pobladas de América durante el período de estudio, aspecto que resulta fundamental en un trabajo referido al consumo de productos básicos. Así, vemos la fluctuación en el número de habitantes debido a la guerra y a las epidemias que se presentaron en el transcurso de esos años.

Ahora bien, una consideración general que se puede hacer al trabajo propuesto por Moncada, investigación por lo demás cuidada y prolija, es que pasa de los últimos años del virreinato casi directamente a la primera república federal, por lo que queda prácticamente fuera del análisis la etapa comprendida entre 1821 y 1824 — salvo por los cuadros y gráficas-, período que incluye el Imperio de Iturbide. Sobre este particular me parece que resulta insuficiente la explicación que presenta la autora en unos pocos renglones de las conclusiones, cuando apunta que el citado período aparece poco en el estudio debido a que no se hallaron cambios relevantes a nivel administrativo municipal sobre el tema que le ocupó. Quizá esto podría solventarse en posteriores investigaciones en las que, como complemento a la presente propuesta, sería muy estimable que se hiciera el esfuerzo por abundar un poco más en lo ocurrido durante el Imperio ya que fue, después de todo, la primera organización política que tuvo el México independiente, a pesar de su corta duración.

De cualquier manera, tal y como se apuntó al comienzo de la presente reseña, esta obra es un esfuerzo importante y bien logrado por acercarse a un tema escasamente tratado en la historiografía: el abasto de alimentos para las grandes ciudades en momentos críticos de su desarrollo. El tema del debate sobre la puesta en práctica y la confrontación de dos sistemas económicos, el proteccionismo y la libertad comercial, ayuda sin lugar a dudas al estudioso a tener un panorama mucho más completo del desarrollo y de los cambios ideológicos que se produjeron en los años de transición comprendidos entre finales del régimen virreinal y las primeras décadas de la vida independiente en el país. 